\title{
OBTENÇÃO E APLICAÇÃO DE ARGILAS MODIFICADAS NA CAPACIDADE DE ADSORÇÃO DE EFLUENTE PETROLÍFERO
}

\author{
R. S. S. CUNHA ${ }^{* 1} ;$ J. D. MOTA²; M. G. F. RODRIGUES ${ }^{3}$ \\ 1,2,3 Universidade Federal de Campina Grande - UFCG, Departamento de Engenharia Química \\ Av. Aprígio Veloso 882- Bodocongó - CEP: 58429-970 - Campina Grande - PB - Brasil. \\ Telefone: (83) 2101-1488 - Fax: 2101-1488 \\ E-mail: rocheliachel@hotmail.com
}

\begin{abstract}
RESUMO - As argilas apresentam viabilidade técnico-econômica decorrente dos seus potenciais de adsorção que, associados as suas disponibilidades, as tornam adsorventes de baixo custo. Por outro lado, na sua forma natural não possui afinidade com compostos orgânicos. Buscou-se desenvolver um material destinado a remoção de compostos orgânicos, (a gasolina efluentes petrolíferos), empregando argilas de Boa-Vista/PB. O material organofílico foi preparado, visando uma efetiva troca catiônica nas suas regiões interlamelares. Para a caracterização das argilas foram feitas as análises de capacidade de troca de cátions, difração de raios X e espectroscopia na região do Infravermelho. Foi avaliado a capacidade de adsorção das argilas na remoção de gasolina com relação ao tempo de contato entre argila/efluente, observou-se que a quantidade média adsorvida para cada argila modificada foi de 5,00 g de solvente para cada grama de argila enquanto as argilas naturais adsorveram em média $1,00 \mathrm{~g}$ do efluente.
\end{abstract}

\section{INTRODUÇÃO}

A poluição por hidrocarbonetos, em particular a exploração de petróleo, tem causado impacto ambiental bastante significativo o que origina uma preocupação pertinente nos dias atuais. Com a exploração do petróleo a poluição em cursos aquáticos tem aumentado conforme Husseien et al. (2009). Um dos subprodutos da produção de petróleo e gás, que inclui quase $98 \%$ de todos os resíduos gerados pela exploração do petróleo e de suas atividades de produção, é a água produzida que tem um grande impacto no nosso ambiente, composta por uma série de hidrocarbonetos. Além disso, as normas de descarga estão cada vez mais rigorosa na maioria das áreas operacionais do mundo. Visando diminuir a geração destes resíduos, o tratamento de água, tornaram-se temas de crescente atenção e interesse nas operações de exploração e produção em todos os lugares conforme (Alter 1997).

Vazamento de derivados de petróleo de tanques de armazenamento, transporte, oleodutos e efluentes petroquímicos introduz uma série de compostos no meio ambiente, incluindo ao ar, solo e água, assim relatados por Aivalioti et al. (2011). Existem preocupações sobre os efeitos adversos à saúde de compostos derivados do petróleo como a gasolina, Benzeno, tolueno, etilbenzeno e xileno (BTEX), incluindo câncer, irritação das membranas mucosas, alterações 
hematológicas, comprometimento do sistema nervoso central, problemas respiratórios e rompimento de fígado e rim efeitos conferidos por Aivalioti et al. (2011) e pela Organização Mundial da Saúde (2004).

Atualmente, vários métodos são utilizados para purificar a água a partir de produtos petrolíferos: métodos mecânicos, físico-químicos, e bioquímicos. As melhores tecnologias disponíveis para a remoção do óleo incluem o tratamento químico, separação por gravidade, coalescedores de placas paralelas, flotação gás, flotação por ar, jato de flotação, eletroflotação, a separação do ciclone, filtração meio granular, filtração cartucho, filtração biológica aerada e adsorção conforme Santander e Rubio (2011) e Su et al. (2007). Entre os métodos físicoquímicos, a adsorção é um dos processos mais interessantes, uma vez que é muito eficiente e pode assegurar a purificação para qualquer nível exigido do processo.

Como materiais adsorventes, as argilas esmectíticas surgem como alternativas no processo de adsorção por possuírem elevada área de superfície e baixo custo como relata Gil et al. (2011). No entanto as argilas naturais possuem a características de ser hidrofílica o que dificulta a remoção de compostos orgânicos por não possuírem afinidade, porém as argilas quando modificadas quimicamente, permite seu uso para diversos tipos de aplicações tecnológicas, resultando grande valor científico e industrial (Lagaly et al. 2006).

As argilas modificadas quimicamente por sais quaternários de amônio remove de maneira eficiente os compostos orgânicos de baixa solubilidade na água como óleos. Apesar de existirem outros tipos de adsorventes para removerem a maioria dos poluentes, alguns são suscetíveis à obstrução dos poros na sua estrutura por hidrocarbonetos grandes. Por esse motivo, as argilas modificadas com sais orgânicos são utilizadas para remoção de compostos provenientes de petróleos, a partir de soluções aquosas (Silva et al. 2011) e (Nguyen et al. 2013).

O objetivo deste trabalho é sintetizar argilas organofílicas (Bofe e chocolate B), a partir de argilas naturais, utilizando o sal orgânico (GENAMIN CTAC-50) e testar a eficiência na capacidade de adsorção na remoção de gasolina comercial.

\section{MATERIAIS E MÉTODOS}

\subsection{Preparação das argilas organofílicas}

Foram utilizadas as argilas Bofe e Chocolate B, fornecidas pela Bentonisa do Nordeste S.A., localizada em Boa Vista, Paraíba. Foi utilizado o sal quaternário de amônio comercial Cloreto de cetil trimetil amônio (Genamin), fornecido pela Clariant. O método utilizado foi o mesmo de Pereira et al. (2007). O procedimento é ilustrado no fluxograma descrito na Figura 1, o qual apresenta as etapas de preparação das argilas organofílicas. 


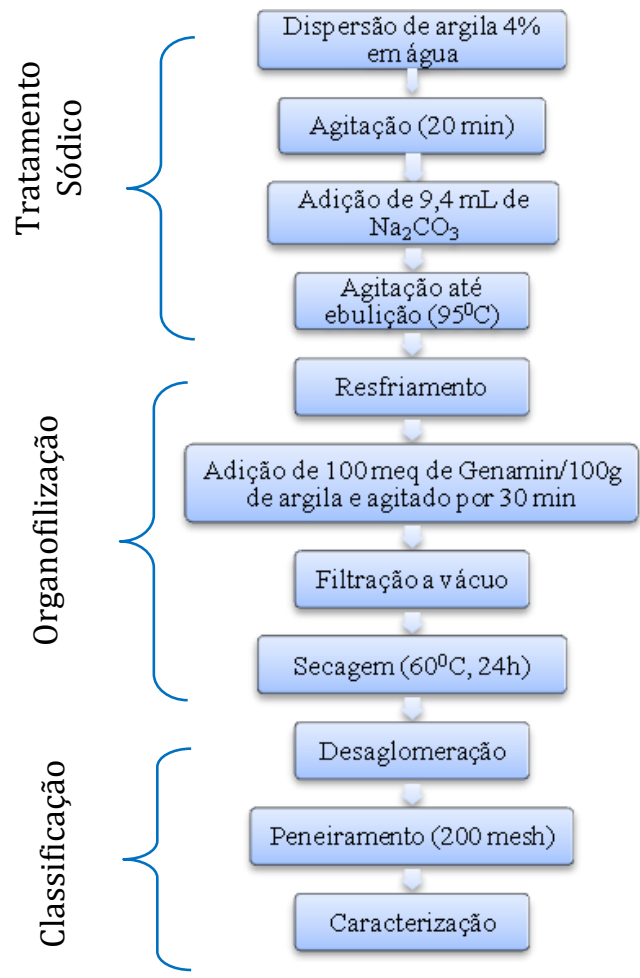

Figura 1 - Fluxograma do processo de produção das argilas organofílicas.

\subsection{Caracterização da Amostra}

Difração de raios $\mathrm{X}(\mathrm{DRX})$ : As amostras de argilas foram peneiradas e colocadas em porta amostra de alumínio para as medições de difração de raios-X. Os padrões de DRX dos materiais foram obtidos no equipamento Shimadzu XRD-6000 com radiação CuKa, tensão de $40 \mathrm{KV}$, corrente de $30 \mathrm{~mA}$, tamanho do passo de 0,020 $2 \theta$ e tempo por passo de 1,000 s, com velocidade de varredura de $2^{\circ}(2 \theta) / \mathrm{min}$, com ângulo $2 \theta$ percorrido de 2 a $50^{\circ}$.

Espectroscopia na Região do Infravermelho (IV): As amostras foram submetidas a um tratamento físico, que consiste na mistura de $0,007 \mathrm{~g}$ de argila e $0,1 \mathrm{~g}$ de $\mathrm{KBr}$, trituração e prensagem da mistura sólida a 5 toneladas durante $30 \mathrm{~s}$, de modo a formar uma pastilha que permite a passagem da luz. A caracterização foi realizada utilizando um espectrofotômetro de infravermelho AVATAR TM 360 ESP FT-IR, na região compreendida de 4000-400 cm . $^{-1}$

\section{Capacidade de Adsorção}

O teste de avaliação da capacidade de adsorção em solvente orgânico foi baseado no "Standard Methods of Testing Sorbent Performance of Adsorbents" baseado nas normas ASTM F716-82 e ASTM F726-9 variando apenas o tempo de contato entre o adsorvente e o adsorbato. Este teste constou do seguinte procedimento: em um recipiente, béquer, onde foi colocado o solvente a ser testado até uma altura de $2 \mathrm{~cm}$. Em uma cesta (fabricada de tela de Aço Inoxidável 
com malha ABNT 200, abertura de 0,075 mm) foi colocado 1,00g do material adsorvente, argila organofílica a ser testado. Esse conjunto foi pesado e colocado no béquer com o solvente, onde permaneceu em contato por $5,10,15,20,25,30,35,40,45,50,55$ e 60 minutos. Após esse tempo, deixou escorrer o excesso por 15 segundos e realizada uma nova pesagem. A quantidade de solvente adsorvida foi calculada a partir da Equação (1).

$$
A d=\left(\frac{P_{1}-P_{2}}{P_{2}}\right) * 100
$$

Em que: $P_{1}$ : Peso do material após adsorção. $P_{2}$ : Peso do material adsorvente seco. $A d$ : Eficiência da adsorção para o fluido e o adsorvente testado, em percentagem.

Os resultados da capacidade de adsorção foram apresentados em gramas de solvente adsorvido por grama de argila.

\section{RESULTADOS}

Com os valores obtidos dos espaçamentos basais é possível verificar e comparar as variações do picos característicos das argilas naturais para as argilas organofílicas. $\mathrm{O}$ valor do espaçamento basal adquirido varia de acordo com o tipo, concentração e orientação do sal quaternário de amônio empregado na metodologia de preparação, (Paiva et al. 2008).

Nas Figuras 2 (a, b) ilustram os difratogramas das argilas Bofe e Chocolate B: natural e organofílica onde apresentam as aberturas das camadas das argilas, logo após a intercalação dos cátions orgânicos. É possível verificar que após o processo de organofilização ocorreu a redução do ângulo $2 \theta$ e, consequentemente, aumento do espaçamento basal decorrente do sal quaternário de amônio, promovendo uma nova abertura nas argilas.

(a)

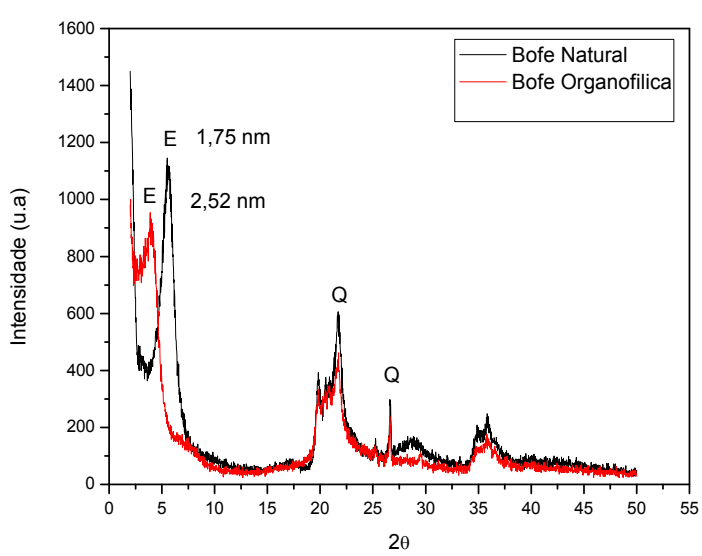

(b)

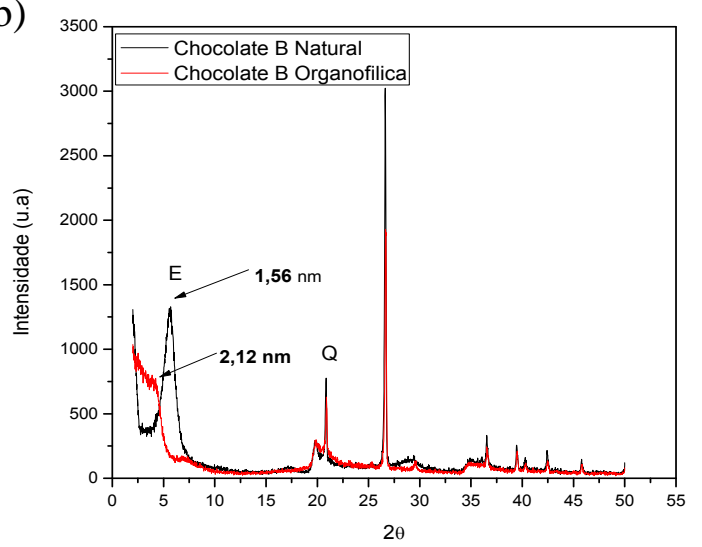

Figura 2 - Difratogramas das argilas Bofe: Natural e Organofílica (a), Difratogramas das argilas Chocolate B: Natural e Organofílica (b). 
Por meio dos difratogramas é possível verificar que as argilas Bofe e Chocolate B natural apresentam reflexão do grupo da esmectita (E) que aparecem em aproximadamente $5,6^{0}$ e corresponde ao espaçamento basal (d001) de $1,75 \mathrm{~nm}$ e $1,56 \mathrm{~nm}$ que é característico de uma montmorilonita hidratada. Observam-se também outros picos que são referentes à mineral não esmectítico como o quartzo que se apresenta como impureza, características encontradas também por (Wang et al. 2004).

Na representação gráfica para as argilas tratadas, pode-se observar que os padrões de DRX, ilustram que após a modificação da argila Bofe natural com sais quaternários de amônio, o deslocamento dos picos de difração ocorreu um aumento do espaçamento basal para 2,52 nm, como pode ser visto em 3,9 (Figura 2a) e a argila Chocolate B ocasionou um aumento do espaçamento basal para 2,12nm (Figura $2 \mathrm{~b}$ ).

O aumento expressivo na $\mathrm{d}(001)$ das amostras obtidas com o sal quaternário evidencia a efetiva intercalação dos cátions quaternários de amônio nas camadas interlamelares das argilas.

Os espectros na região do infravermelho das amostras das argilas Bofe e Chocolate B: natural e organofílica estão apresentados na Figura 3 (a, b).

(a)

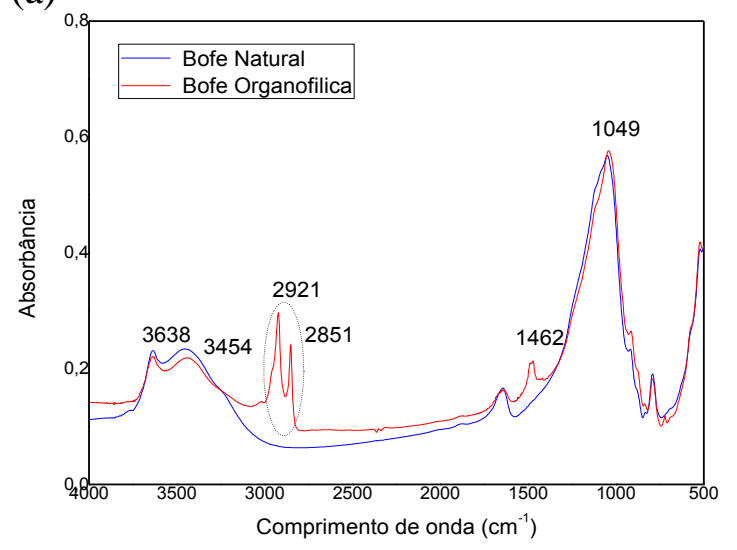

(b)

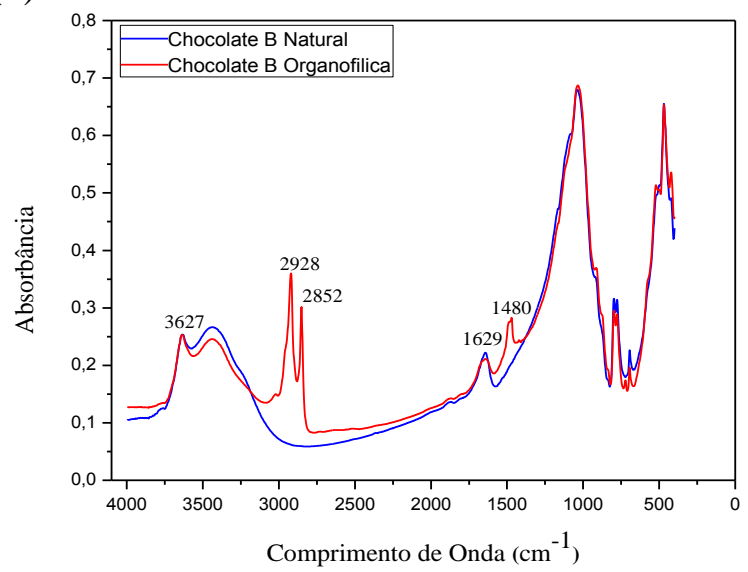

Figura 3 - Espectros na região do infravermelho das argilas Bofe: natural e organofílica (a) e argila Chocolate B (b).

Analisando os espectros na região do infravermelho das amostras que estão representados nas Figura 3 (a, b), é possível verificar que existem bandas na região de $3640-3400 \mathrm{~cm}^{-1}$, que são relativas ao grupo $\mathrm{OH}$ livre ou combinado. Estas bandas são atribuídas a vibrações de estiramento do grupo funcional $\mathrm{OH}$ da água no interior das esmectitas. Bandas presente nas argilas organofílica, indicando a manutenção da estrutura após a organofilização. A diminuição na intensidade das bandas referentes à mesma região nas argilas naturais para as organofílicas 
refletem apenas mudanças nas características da superfície das mesmas, de hidrofílicas para hidrofóbicas, Bertagnolli et al. (2009). Já as bandas que surgem após o processo de organofilização próximas a região de $2950-2800 \mathrm{~cm}^{-1}$ são características dos estiramentos das ligações $\mathrm{CH}_{2}$. As bandas próximas a $2900 \mathrm{~cm}^{-1}$ são relativas ao estiramento assimétrico, e as bandas próximas a $2800 \mathrm{~cm}^{-1}$ ao simétrico, Leite et al. (2008). Já as bandas próximas a $1480 \mathrm{~cm}^{-1}$ estão relacionadas à flexão do grupo $\mathrm{CH}_{3}$, indicando a presença do surfactante nas argilas, conforme Zhou et al. (2008). As bandas presentes na região próxima a $1045 \mathrm{~cm}^{-1}$ são características das ligações $\mathrm{Si}-\mathrm{O}-\mathrm{Si}$ e as próximas à região $530 \mathrm{~cm}^{-1}$ são correspondentes às características das camadas octaédricas do aluminossilicato Si-O-Al, (Kozak e Donka 2004).

As Figuras $4(\mathrm{a}, \mathrm{b})$ ilustram os resultados obtidos, da capacidade de adsorção das argilas Bofe e Chocolate B naturais e organofílicas em solvente orgânico gasolina comercial.

(a)

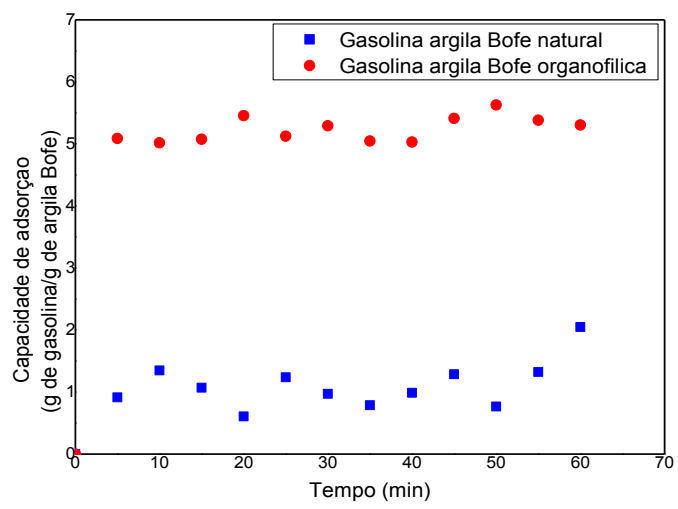

(b)

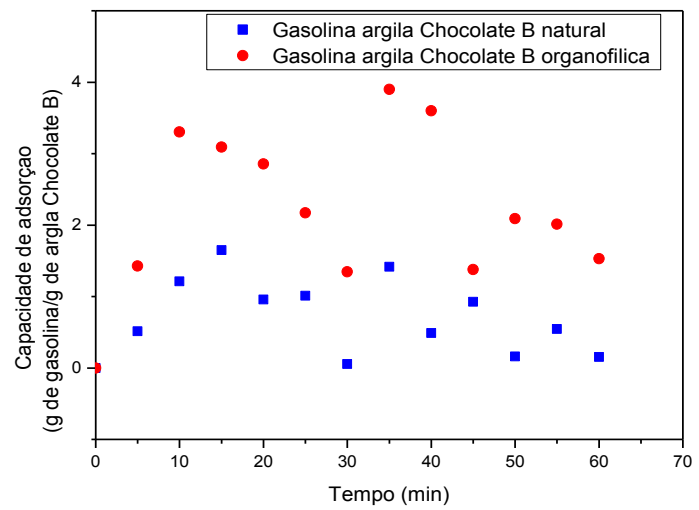

Figura 4 - Capacidade de adsorção das argilas Bofe natural e organofílica (a) e argila Chocolate

B natural e organofílica (b) na remoção de gasolina.

É possível verificar, a partir dos dados apresentados na Figura 4, uma adsorção bastante rápida independente do adsorvente utilizado (argila natural ou argila organofílica).

Ao comparar as duas curvas, observa-se que a quantidade total de gasolina adsorvida utilizando as argilas organofílicas foram maiores do que quando utilizado argilas naturais. Foram adsorvidos em média com a utilização das organofílicas 5,23 g de gasolina por grama de argila Bofe e 2,21g de gasolina por cada grama de argila Chocolate B, enquanto que na argila natural a capacidade de adsorção ao longo do tempo de contato apresentou em média apenas $1,11 \mathrm{~g}$ de gasolina por cada grama de argila Bofe natural e a argila chocolate B 0,70 g de gasolina por cada grama de argila. Estes resultados estão em concordância com os encontrados na literatura (Rodrigues et al. 2010) e (Oliveira et al. 2012). 
Resultados estes que evidenciam que o processo de organofilização promove o potencial da argila modificada com sais orgânicos na remoção de compostos orgânicos, sendo, portanto mais uma alternativa para processos adsortivos de contaminantes orgânicos.

\section{CONSIDERAÇÕES FINAIS}

A partir do DRX foi possível verificar mudanças significativas nos valores das distâncias interplanares das esmectitas, devido à intercalação do sal quaternário de amônio na estrutura interlamelar das argilas.

De acordo com a espectroscopia na região do infravermelho verifica-se o surgimento de novas bandas de $\mathrm{CH}_{2}$ e $\mathrm{CH}_{3}$, que correspondem ao sal quaternário de amônio.

As eficiências da capacidade de adsorção mostraram que as argilas Bofe e Chocolate B organofílica adsorveram o solvente orgânicos estudado (gasolina) mais eficientemente do que em sua forma natural.

\section{REFERÊNCIAS}

GIL. A.; F. ASSIS.; S. ALBENIZ.; S. KORILI. Removal of dyes from waste water by adsorption on clays pillared. Chem. Eng. J. v.168, p. 1032-1040, 2011.

BERTAGNOLli, C.; KLEINÜBING, S. J.; SILVA, M. G. C. Preparo e avaliação de argilas Verde-Lodo organofílicas para uso na remoção de derivados de petróleo. Scientia Plena, v. 5, p.1-7, 2009.

SU. D.; J. WANG.; K. LIU.; D. ZHOU. Kinetic Performance of oil field produced water treatment by biological aerated filter. Chin. J. Chem. Eng. v.15, p. 591-594, 2007.

ALTER, GR. Organophilic cost effectively removes oil from produced water. Oil Gas J. v. 95, p.15-25, 1997.

KOZAK, M.; DONKA, L. Adsorption of the quaternary ammonium salts on montmorillonite. J. Phys. Chem. S., v.65, p.441-445, 2004.

LAGAlY, G.; BERGAYA, F.; THENG, B. K. G. Handbook of Clay Science. Developments in Clay Science, Elsevier Science, Amsterdam, v. 1, 2006.

LEITE, I. F.; RAPOSO, C. M. O.; SILVA S. M. L. Caracterização estrutural de argilas bentoníticas nacional e importada: antes e após o processo de organofilização para utilização como nanocargas. Cerâmica, v.54, p.303-308, 2008. 


\section{9 a 22 de outubro de 2014 \\ Florianópolis/SC}

AIVALIOTI, M.; D. POTHOULAKI.; P. PAPOULIAS. Removal of BTEX, MTBE and TAME from aqueous solutions by adsorption onto raw and thermally treated lignite. J. Hazard. Mater. v. 208, p.136-146, 2011.

HUSSEIEN M.; AA AMER.; A. EL-MAGHRABY. Taha Availability of barley straw application on oil spill clean up. J. Environ. Sci. Technol. v. 6, p. 123-130, 2009.

SANTANDER, RT.; RODRIGUES, J. RUBIO. Modified jet flotation oil (petroleum) separations water emulsion. Coll. Surf. A, v. 375 p. 237-244, 2011.

NGUYEN, V. N.; NGUYEN, T. D. C.; DAO, T. P.; THUAN, H. T.; BANG, D. N.; AHN, D. H. Synthesis of organoclays and their application for the adsorption of phenolic compounds from aqueous solution. J. Ind.Eng.Chem. v. 19, p. 640-644, 2013.

OLIVEIRA, G. C.; MOTA, M. F.; SILVA, M. M.; RODRIGUES, M. G. F.; LABORDE, H. M. Performance of natural sodium Clay treated with ammonium salt in the separation of emulsified oil in water. Oil Gas J. B. v. 6, p. 171-183, 2012.

Organização Mundial da Saúde, Diretrizes para a qualidade da água potável: Organização Mundial de Saúde, Distribuição e Vendas, Genebra 27, Suíça CH-1211, 2004.

PAIVA, L. B.; MORALES, A. R.; VALENZUELA-DÍAZ, F. R. Argilas organofílicas: características, metodologias de preparação, compostos de intercalação e técnicas de caracterização. Cerâmica, v.54, p. 213-226, 2008.

PEREIRA, K. R. O.; RODRIGUES, M. G. F.; VALENZUELA-DiAZ, F. R. Síntese e caracterização de argilas organofílicas: comparação no uso de dois métodos. Rev. Elet. Mat. Proc, v. 2, p. 1-8, 2007.

RODRIGUES, S. C. G.; RODRIGUES, M. G. F.; PEREIRA, K. R. O.; ALENZUELA-DÍAZ, F. R. Performance or organophilic Clay as adsorbent in the oil/water separation process. Oil Gas J. B. v.4, p.49-58, 2010.

SILVA, M. M.; PATRÍCIO, A. C. L.; LIMA, W. S.; LABORDE, H. M.; RODRIGUES, M. G. F. Preparação e avaliação da argila verde organofílica usando diferentes concentrações de surfactante catiônico visando seu uso na separação óleo/água. Scientia Plena, v. 7, p.171-180, 2011.

WANG, C. C.; JUANG, L. C.; LEE, C. K.; HSU, T. C.; LEE, J. F.; CHAO, H. P. Effects of Exchanged Surfactant Cations on the Pore Structure and Adsorption Characteristics of Montmorillonite. J. Coll. I. Sc., v.280, p. 27-35, 2004.

ZHOU, Q.; XI, Y.; HE, H.; FROST, R. Application of near infrared spectroscopy for the determination of adsorbed $p$-nitrophenol on HDTMA organoclays-implications for the removal 
of organic pollutants from water. Spectr. Acta Part. v.69, p.835-841, 2008. 